\title{
Missing-in-metastasis B (MIM-B) combined with caveolin-1 promotes metastasis of hepatocellular carcinoma
}

\author{
Xiu-Yan Huang ${ }^{1, *}$, Zi-Li Huang ${ }^{2, *}$, Tao Niu ${ }^{3, *}$, Zhen-Qian $\mathbf{W u}^{1, *}$, Bin $\mathrm{Xu}^{4, *}$, Yong-Hua \\ $X^{2}{ }^{2}$, Xin-Yu Huang ${ }^{1}$, Qi Zheng ${ }^{1}$, Jian Zhou ${ }^{5}$, Zi Chen ${ }^{6}$ and Zhao-You Tang ${ }^{5}$ \\ ${ }^{1}$ Department of General Surgery, Shanghai Jiaotong University Affiliated Sixth People's Hospital, Shanghai, P.R. China \\ ${ }^{2}$ Department of Radiology, Xuhui Central Hospital, Shanghai, P.R. China \\ ${ }^{3}$ Department of General Surgery, People's Hospital of Menghai County, Yunnan Province, P.R. China \\ ${ }^{4}$ Department of General Surgery, The Tenth People's Hospital of Tongji University, Shanghai, P.R. China \\ ${ }^{5}$ Liver Cancer Institute and Zhongshan Hospital, Fudan University, Shanghai, P.R. China \\ ${ }^{6}$ Thayer School of Engineering, Norris Cotton Cancer Center, Dartmouth College, Hanover, NH, USA \\ *These authors have contributed equally to this work \\ Correspondence to: Xiu-Yan Huang, email: xyhuang1119@163.com \\ Keywords: hepatocellular carcinoma; missing in metastasis B; caveolin-1; epidermal growth factor receptor; metastasis \\ Received: December 14, $2016 \quad$ Accepted: August 04, $2017 \quad$ Published: September 08, 2017 \\ Copyright: Huang et al. This is an open-access article distributed under the terms of the Creative Commons Attribution License \\ 3.0 (CC BY 3.0), which permits unrestricted use, distribution, and reproduction in any medium, provided the original author and \\ source are credited.
}

\section{ABSTRACT}

Background: Increasing amounts of evidence indicate that Missing in metastasis B (MIM-B) promotes cancer metastasis. Here, we sought to better understand the mechanism through which MIM-B promotes tumor metastasis in hepatocellular carcinoma (HCC).

Methods: We performed confocal microscopy analysis to determine the distributions of MIM-B and caveolin-1 and conducted co-immunoprecipitation assays to detect the interactions between MIM-B and caveolin-1 in vitro. We performed transwell assays to analyze the invasive ability of HCC cells. Changes in the expression levels of key genes and some molecular makers were detected by immunohistochemistry and western blotting in HCC tissue samples.

Results: We found that MIM-B co-localizes with caveolin-1 and demonstrated that MIM-B and caveolin-1 interact in vitro. Repressing MIM-B and caveolin-1 expression inhibited the epidermal growth factor receptor signaling pathway. We overexpressed MIM-B and caveolin-1 in Hep3B cells, which enhanced Hep3B cell invasiveness. Furthermore, MHCC97H cell invasiveness was significantly decreased in cells in which MIM-B and caveolin-1 expression was inhibited. Additionally, we found that MIM-B and caveolin-1 were expressed at higher levels in HCC tissues than in paired normal tissues. Moreover, HCC patients with MIM-B and caveolin-1 up-regulation experienced significantly worse outcomes than controls $(P<0.001)$, and HCC patients with high MIM-B and caveolin-1 expression levels often developed pulmonary metastasis $(P<0.001)$.

Conclusions: MIM-B combined with caveolin-1 promotes metastasis of HCC, and elevated MIM-B and caveolin-1 expression levels are associated with a poor prognosis in HCC patients; therefore, MIM-B and caveolin-1 may represent novel targets for the diagnosis and treatment of HCC. 


\section{INTRODUCTION}

Primary liver cancer is one of most commonly diagnosed cancers and is also one of the leading causes of cancer-related death worldwide. Hepatocellular carcinoma (HCC) is the most common type of primary liver cancer and accounts for approximately $75 \%$ of liver tumors [1]. Hepatic resection is currently the most frequently used treatment for patients with HCC [2]. However, HCC is usually diagnosed at an advanced stage, which limits the effectiveness of this treatment. Thus, the rates of $\mathrm{HCC}$ recurrence and metastasis are very high at 5 years after surgery, even among patients who have undergone radical hepatic resection [3]. Therefore, the post-resection biological features of HCC warrant further study.

Metastasis suppressor 1 (MIM-B, also known as missing in metastasis B) was found to be a potential metastasis suppressor in bladder cancer $[4,5]$. The MIM gene encodes a 5.3-kb mRNA molecule, and the following three alternatively spliced isoforms of MIM are found in humans: MIM-A, MIM-B and MIM-C. MIM-B is the most common type of MIM [6]. Several studies have reported that MIM-B expression is altered in a variety of tumors, such as bladder, prostate, colorectal, ovarian, breast, neck, and gastric tumors; basal cell carcinoma; and non-small cell lung cancer, as well as HCC [4-14]. However, the role of MIM-B in different cancers seems to be a subject of controversy, as some reports have proposed that MIM-B is a potential metastasis suppressor, while others have shown that MIM-B may promote tumor metastasis [12, 14-18]. MIM-B contains multiple functional motifs, including an N-terminal IRSp53/MIM domain motif (IMD) and a C-terminal Wiskott-Aldrich syndrome protein homology 2 motif (WH2) [19]. Because of these functional motifs, MIM-B is also postulated to be an important regulator of the actincytoskeleton [20-22].

Caveolin-1, a 21-24-kDa membrane protein, is a member of the caveolin family of proteins and is also the main structural component of caveolae [23-25]. Caveolin-1 plays key roles in several cellular processes, such as caveolae-mediated vesicular transport and endocytosis, lipid metabolism, cell adhesion, cell migration, cell signaling platform regulation, cell transformation, cell proliferation, cell cycle arrest, anchorage-independent growth and apoptotic cell death $[26,27]$. Recent reports showed that caveolin-1 is a candidate tumor suppressor gene and participates in the pathogenesis of oncogenic cell transformation and tumorigenesis. Moreover, several reports have documented that caveolin-1 expression is altered in various cancers, such as bladder, ovarian, thyroid follicular, breast, esophageal, lung, colon, cervical, and renal cancer; $\mathrm{T}$ cell leukemia; and HCC [25, 27-31]. Notably, caveolin-1 has different functions in variety of cancers and may act both as a tumor suppressor and as a tumor-promoting gene. In recent years, several in vitro and in vivo studies have demonstrated that highly expressed caveolin-1 plays an important role in tumor cell survival and tumor growth, tumor aggressiveness, tumor metastatic potential, and tumor apoptosis and is associated with enhanced metastatic potential and poorer patient prognoses [31-35]. However, little is known about the molecular mechanisms governing the function of caveolin-1 in HCC.

The epidermal growth factor receptor (EGFR, also known as ErbB1), a 170-kDa transmembrane tyrosine kinase receptor, is a member of the receptor tyrosine kinases family and promotes cell proliferation, migration, and differentiation in variety of cancers [36-40]. Previous studies have demonstrated that MIM-B can activate the EGFR pathway in Drosophila oocyte border cell migration and endocytosis [41], and another work reported that MIM-B not only promoted EGFR expression in early stage HNSCC cells/tumors but also inhibited EGFR signaling at high cell densities [20, 42]. Moreover, previous studies have demonstrated that the role of caveolae in endocytosis was independent of the EGFR internalization pathway $[43,44]$ and that caveolin-1 can be co-localized with the endosomal EGFR and act upon internalized EGF endosomes $[28,45,46]$. Therefore, we are interested in determining the roles of MIM-B and caveolin-1 in the regulation of EGFR signaling.

In this study, we sought to better understand how MIM-B regulates tumor metastasis. We demonstrated that MIM-B and caveolin-1 co-localize in HCC. We also verified that MIM-B and caveolin-1 interact in vitro. Moreover, we investigated the relationships between MIM-B and caveolin-1 and EGFR signaling and found that inhibiting MIM-B and caveolin-1 repressed EGFR pathway activity. In addition, we demonstrated that repression in MIM-B and caveolin-1 expression levels could inhibit MHCC97H cell migration. Furthermore, we showed that MIM-B and caveolin-1 were expressed at higher levels in cancer tissues than in paired adjacent normal tissues and that MIM-B and caveolin-1 expression levels were correlated with HCC clinico-pathologic characteristics. We also showed that patients with HCC with MIM-B and caveolin-1 up-regulation experienced significantly worse outcomes and had lower survival rates than patients with HCC without MIM-B and caveolin-1 up-regulation. Thus, the interactions between MIM-B and caveolin-1 play an important role in HCC cell invasion.

\section{RESULTS}

\section{MIM-B interacted with caveolin-1 in vitro}

We performed cell immunofluorescence assays to detect the distributions of MIM-B and caveolin-1 in MHCC $97 \mathrm{H}$ cells. The results, as demonstrated by confocal microscopy, showed that MIM-B and caveolin-1 are colocalized in MHCC97H cells (Figure 1A). 
A

MIM-B

Caveolin-1

Merge
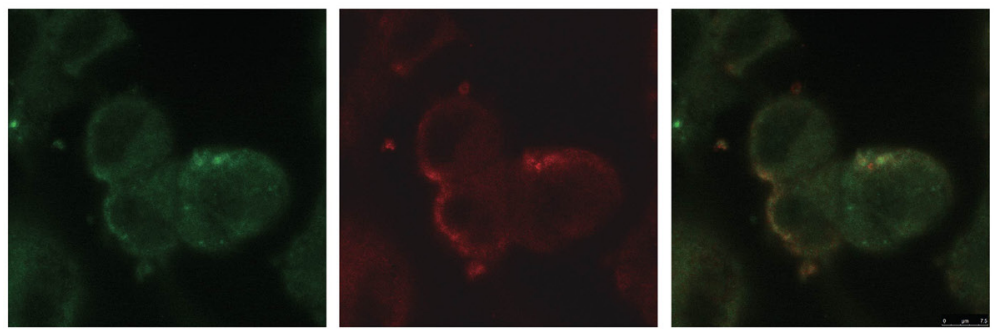

B
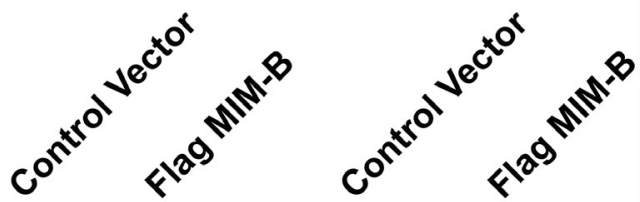
IB: Caveolin-1
IP
IB: Flag
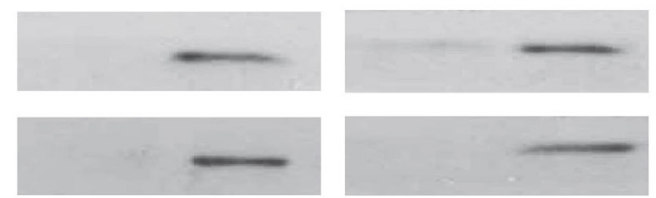
| IB: Caveolin-1
Input
IB: Flag

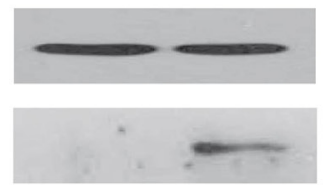

Hep3B

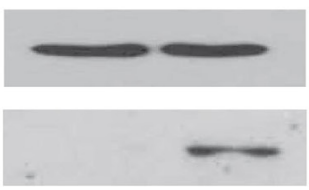

SMMC7721

C

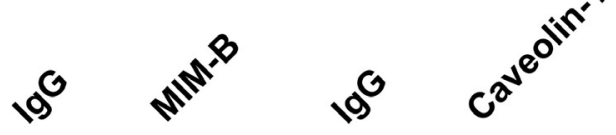

IB: MIM-B

IP

IB: Caveolin-1

Input $\mid \begin{aligned} & \text { IB: } \quad \text { MIM-B } \\ & \text { IB: Caveolin-1 }\end{aligned}$
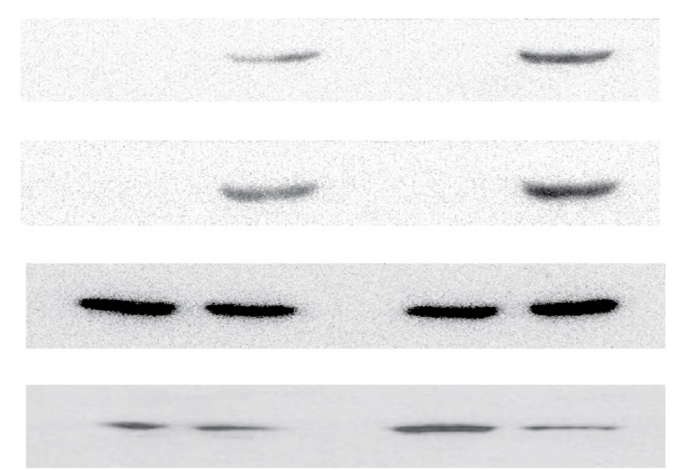

MHCC97H

Figure 1: MIM-B interacted with caveolin-1 in vitro. (A) The distributions of MIM-B and caveolin-1 in HMCC97H cells were analyzed by confocal microscopy. Scalebar, $10 \mu \mathrm{m}$. (B) Co-IP assay of the interactions between MIM-B and caveolin-1 in vitro. As shown on the left and right, anti-Flag antibodies were used for immunoprecipitation, and anti-caveolin-1 antibodies were used for immunoblotting in Hep3B and SMMC7721 cells, respectively. (C) Co-IP assay of the interactions between MIM-B and caveolin-1 in vitro. As shown on the left and right, anti- MIM-B and anti-caveolin-1 affinity matrices were used for immunoprecipitation, respectively. In this experiment, the input samples were used as controls. Each experiment was repeated a minimum of three times. 
Given that caveolin-1 is co-localized with MIM-B, we proposed that MIM-B interacted with caveolin-1. To test this hypothesis, we performed Co-IP assays to confirm that MIM-B interacted with caveolin-1 in vitro. We transfected Flag-tagged MIM-B into the indicated cells and examined the interactions between MIM-B and caveolin-1. The results showed that endogenous caveolin-1 interacted with Flag-MIM-B (Figure 1B). Furthermore, we performed Co-IP experiments in MHCC97H cells. As expected, we found that anti-human MIM-B polyclonal antibodies could precipitate endogenous caveolin-1 protein and that anti-human caveolin-1 polyclonal antibodies could precipitate endogenous MIM-B protein in MHCC97H cells (Figure 1C). Taken together, these results demonstrated that MIM-B interacts directly with caveolin-1 in HCC cell lines.

\section{The IMD and WH2 domains of MIM-B are essential for the interactions between MIM-B and caveolin-1}

Recent reports have shown that the IMD and WH2 motifs of MIM-B may play a role in the interactions between MIM-B and other proteins to modulate cellular processes, such as cancer metastasis and cytoskeletal dynamics [15, 47]. Therefore, we constructed MIM-B sequences lacking IMD or WH2 and studied the roles of each motif in the interactions between MIM-B and caveolin-1 (Figure 2A). qRT-PCR showed that the truncated proteins were expressed successfully in HEK293 cells (Figure 2B), and the Co-IP results showed that deletion of either IMD or WH2 decreased the interactions between MIM-B and caveolin-1 (Figure 2C). These results demonstrated that the IMD and $\mathrm{WH} 2$ motifs are important for the interactions between MIM-B and caveolin-1.

Taken together, these results showed that MIM-B could interact with caveolin-1 in vitro and that the IMD and WH2 motifs of MIM-B are required for the interactions between the two proteins.

\section{Inhibition of MIM-B and caveolin-1 repressed EGFR pathway activity}

Given that caveolin-1 interacted with MIM-B, we tested whether caveolin-1 can modulate EGFR pathway activity. We screened for shRNAs that can knock down MIM-B and caveolin-1 expression in MHCC97H cells using lentiviruses. qPCR analysis showed that shRNA against MIM-B or caveolin-1 could inhibit MIM-B (Figure $3 \mathrm{~A}$ ) or caveolin-1 expression (Figure 3B), respectively.

To elucidate the possible effects of MIM-B and caveolin-1 on the EGFR pathway, we tested the protein expression levels and phosphorylation statuses of the following four well-characterized EGFR subfamily proteins: EGFR, STAT3, AKT and ERK. Interestingly, we found that p-EGFR, p-STAT3, p-AKT and p-ERK
A

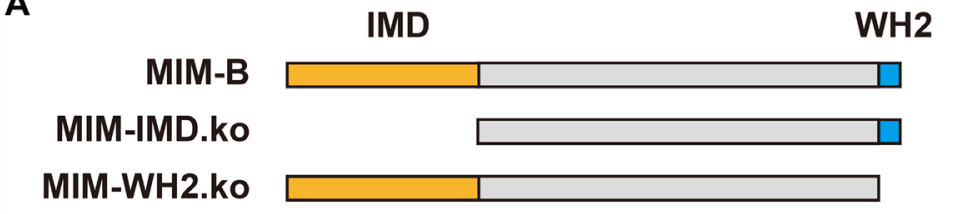

C

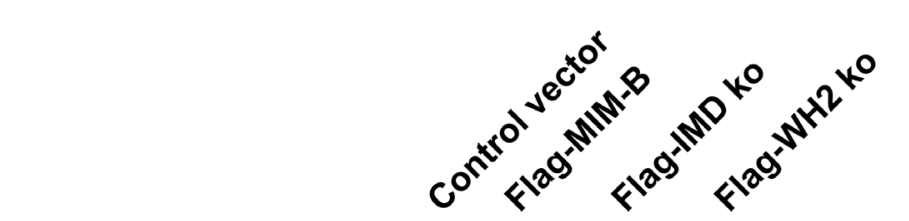

B

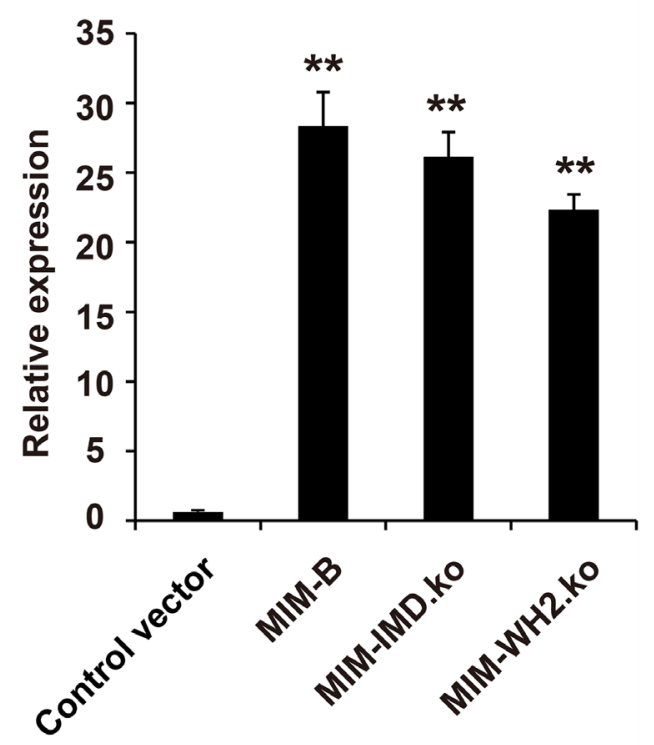

Figure 2: The IMD and WH2 domains are essential for the interactions between MIM-B and caveolin-1. (A) Diagram showing the construction of the mutant MIM-B plasmid. (B) RT-qPCR analysis of the mutant in transaction in HEK293 cells. (C) Co-IP assay of the influence of the IMD and WH2 motifs on the interaction between MIM-B and caveolin-1. In this experiment, the input samples were used as controls. ${ }^{*} P<0.05,{ }^{* *} P<0.01$, and each experiment was repeated at least three times. 

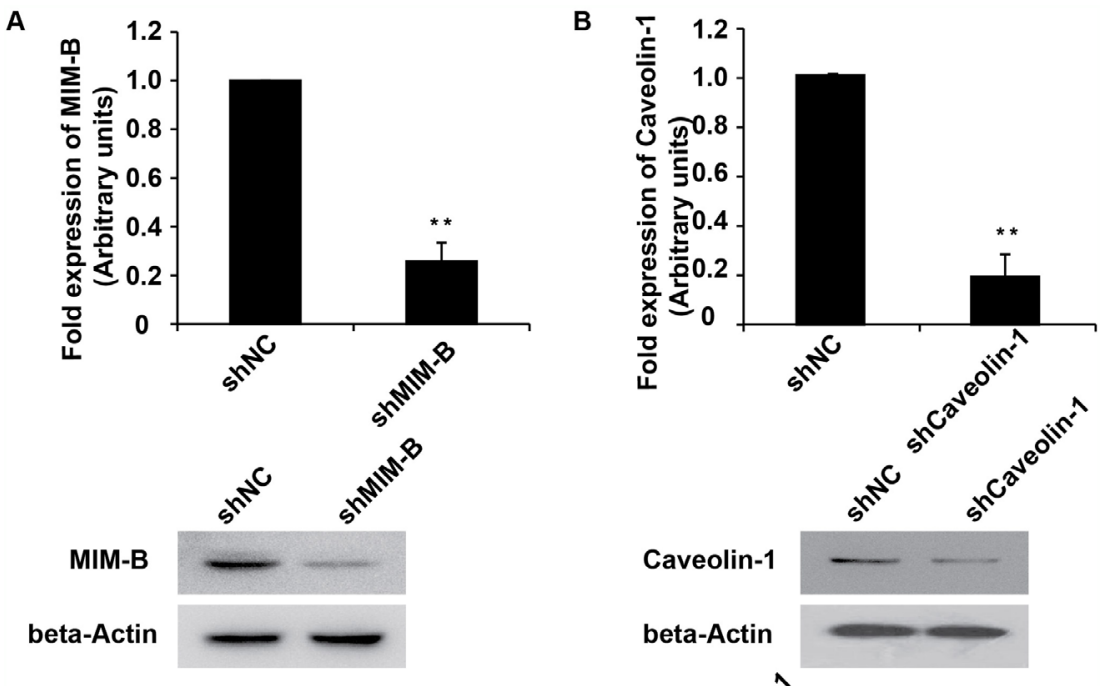

C
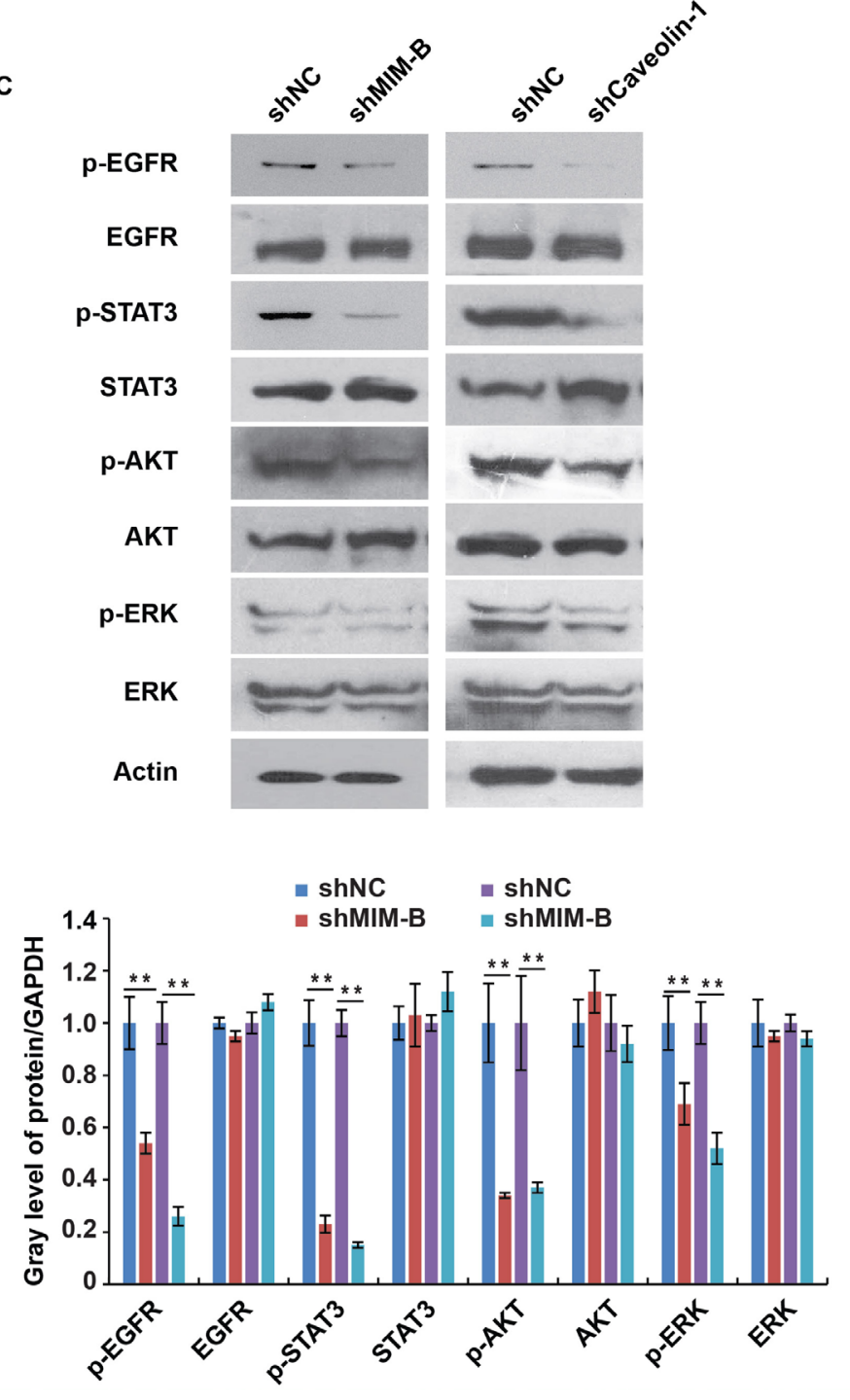

Figure 3: Inhibition of MIM-B and caveolin-1 repressed EGFR pathway activity. (A) qRT-PCR and western blot analyses of MIM-B expression in MHCC97H cells transfected with shRNAs against MIM-B for approximately 48 h. (B) qRT-PCR and western blot analyses of caveolin-1 expression in MHCC97H cells transfected with shRNAs against caveolin-1 for approximately 48 h. (C) The expression levels of EGFR, STAT3, AKT and ERK and their phosphorylated counterparts were examined in cells transfected with shRNAMIM-B and caveolin-1 for approximately $48 \mathrm{~h} .{ }^{*} P<0.05,{ }^{* *} P<0.01$, and each experiment was repeated at least three times. 
expression levels were significantly decreased in MHCC97H cells when MIM-B and caveolin-1 were knocked down (Figure 3C).

Taken together, these results demonstrated that both MIM-B and caveolin-1 stimulated the EGFR pathway.

\section{Alterations in MIM-B and caveolin-1 expression levels affect $\mathrm{HCC}$ cell migration}

Given that MIM-B interacts with caveolin-1 in HCC cells, we investigated whether MIM-B and caveolin-1 affect HCC cell invasion and metastasis. We over-expressed MIM-B and caveolin-1 in Hep3B cells and performed cell migration assay, the results of which showed that Hep3B cell metastasis was significantly increased in the corresponding cells compared with control cells (Figure 4A and 4B), demonstrating that MIM-B and caveolin-1 could promote Hep3B cell migration. Furthermore, we downregulated MIM-B expression and found that MHCC97H cell migration (Figure 5A, lanes 1 and 2) and MHCC97H cell invasion (Figure 5B, lanes 1 and 2) were decreased in the corresponding cells compared with control cells. These results demonstrated that MIM-B positively promoted MHCC $97 \mathrm{H}$ cell invasion. To determine the role of caveolin-1 in MHCC97H cell invasion, we reduced caveolin-1 expression and found that $\mathrm{MHCC} 97 \mathrm{H}$ cell metastasis was inhibited in the corresponding cells compared with control cells (Figure $5 \mathrm{~A}$ and $5 \mathrm{~B}$, lanes 1 and 3 ). These results showed that caveolin-1 enhances MHCC $97 \mathrm{H}$ cell invasiveness.

To determine the importance of MIM-B and caveolin-1 in MHCC97H cell invasiveness, we knocked down MIM-B and caveolin-1 expression simultaneously, and found that $\mathrm{MHCC} 97 \mathrm{H}$ cell migration and invasiveness were significantly decreased in the corresponding cells compared with control cells (Figure 5, lanes 1 and 4).

Taken together, these results indicate that altering MIM-B and caveolin-1 expression affected HCC cell migration.

\section{Correlation between MIM-B and caveolin-1 expression in $\mathrm{HCC}$}

To determine the clinical significance of MIM-B and caveolin-1 expression in HCC, we examined MIM-B and caveolin-1 expression in HCC tissues. The correlations between MIM-B and caveolin-1 expression levels, as determined by IHC, and HCC clinico-pathologic characteristics of HCC are summarized in Table 1. The majority of patients with HCC had high MIM-B ( $\mathrm{n}=49$, $49 / 84,58.3 \%)$ or caveolin-1 expression levels $(\mathrm{n}=53$, $53 / 84,63.1 \%)$. Twenty-five $(25 / 38,65.8 \%)$ of 38 cases of HCC with a tumor size $<5 \mathrm{~cm}$ presented with high MIM-B expression, while $24(24 / 46,52.2 \%)$ of 46 cases of HCC with a tumor size $\geq 5 \mathrm{~cm}$ presented with high MIM-B expression. High MIM-B and caveolin-1 expression was correlated with tumor satellites $(P=0.005)$, numbers $(P$ $=0.006)$, encapsulation $(P=0.027)$, vascular invasion $(P$ $=0.001)$ and TNM stage $(P=0.002)$. We also observed that pulmonary metastasis was more common in HCC with high MIM-B expression levels $(28 / 40,70 \%)$ than in HCC with lower MIM-B expression levels (12/40, 30\%; $P=0.039)$ and in HCC with high caveolin-1 expression levels $(32 / 40,80 \%)$ than in HCC with lowers caveolin-1 expression levels $(8 / 40,20 \% ; P=0.002)$. Furthermore, the majority of patients with pulmonary metastasis $(27 / 38$, $71.1 \% ; P<0.001)$ had both high MIM-B expression and high caveolin-1 expression. Taken together, these data demonstrated that MIM-B and caveolin-1 levels were associated with HCC clinico-pathologic characteristics.

To elucidate the possible roles of MIM-B and caveolin-1 expression with in HCC tissues, we compared their expression levels in clinical HCC samples and paired adjacent normal tissues. We found that MIM-B and caveolin-1 were differentially expressed between tumor tissues and normal tissues (Figure 6A-6D). We noted elevated MIM-B expression in 49 of 84 patient samples and increased caveolin-1 expression in 53 of 84 patient samples $(P<0.001$, Figure $6 \mathrm{~A}$ and $6 \mathrm{~B})$. Consistent with the data obtained from IHC, we found that MIM-B and caveolin-1 were significantly elevated and co-localized in HCC tissue samples when compared with matched adjacent normal tissues $(P<0.001$, Figure 6D). Taken together, these results demonstrated that MIM-B and caveolin-1 expression levels were higher in cancer tissues than in paired adjacent normal tissues and that MIM-B and caveolin-1 expression levels were correlated with HCC clinico-pathologic characteristics.

To confirm whether the combination of MIM-B and caveolin-1 can serve as a prognostic factor for HCC, we analyzed the overall survival of patients with different levels of MIM-B and caveolin-1 expression using the Kaplan-Meier method (log-rank test). We found that MIM-B and caveolin-1 expression levels were associated with overall survival (Figure 7). Patients with high MIM-B expression revealed poorer prognosis when compared with patients with low MIM-B expression $(P<0.0001$, Figure 7); patients with high caveolin-1 expression revealed poorer prognosis when compared with patients with low caveolin-1 expression $(P<0.00001$, Figure 7). The median survival durations in the low MIM-B and caveolin-1 expression groups were NA and 62 months respectively, while the mean survival durations in the high MIM-B and caveolin-1 expression groups were 24 and 27 months, respectively. Moreover, the mean survival duration in the high MIM-B + caveolin-1 expression group was 19 months $(P<0.01)$.

Collectively, these results demonstrated that MIM-B/caveolin-1 expression may be an independent prognostic factor for HCC, as well as a novel therapeutic target in the treatment of HCC. 
A

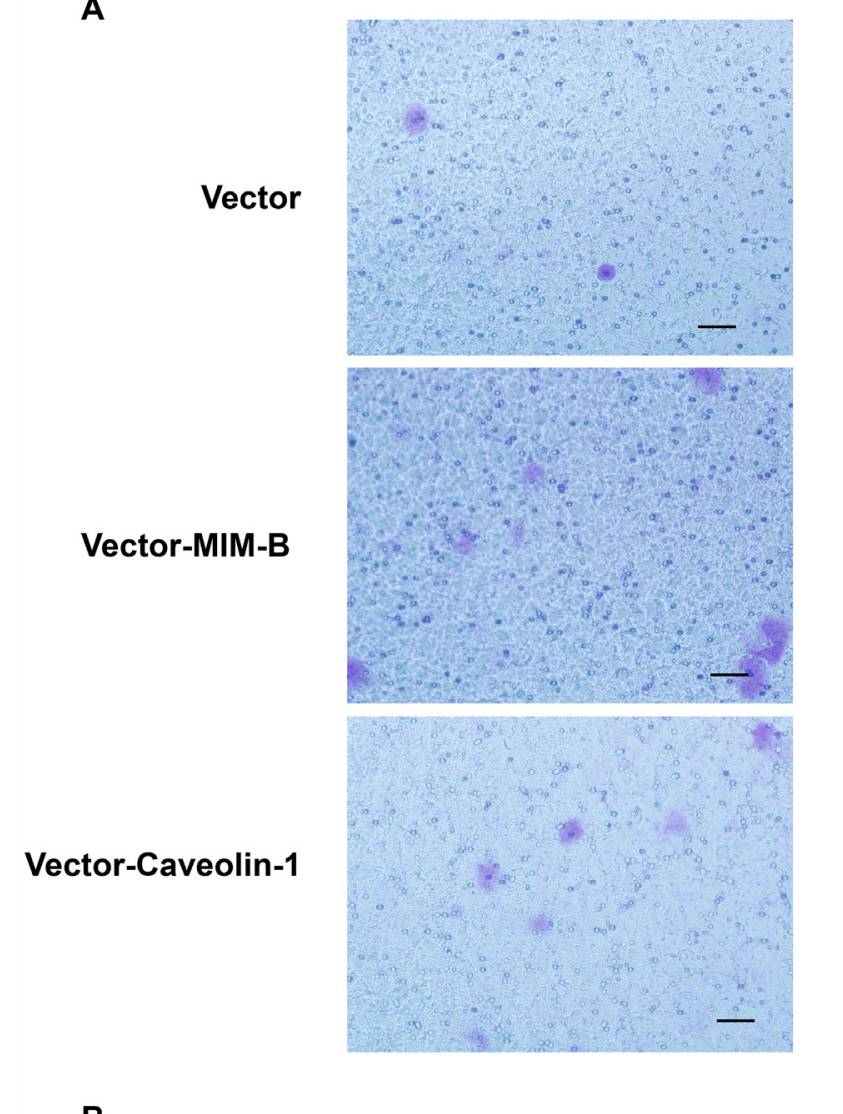

B

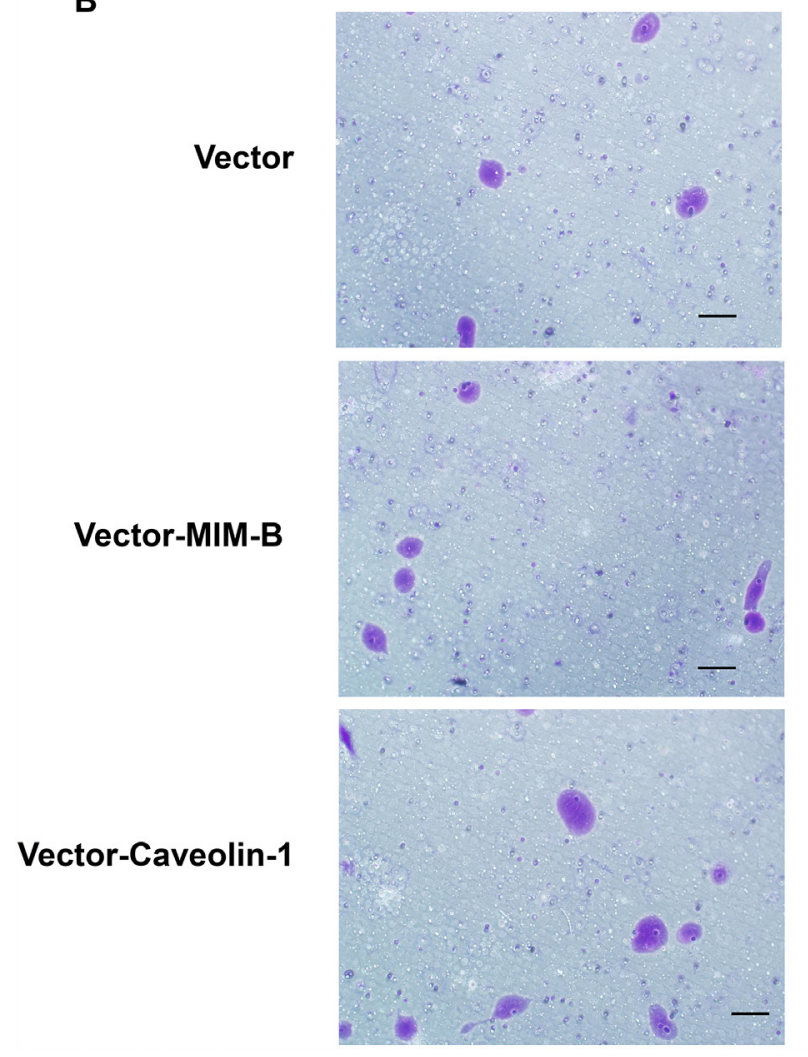

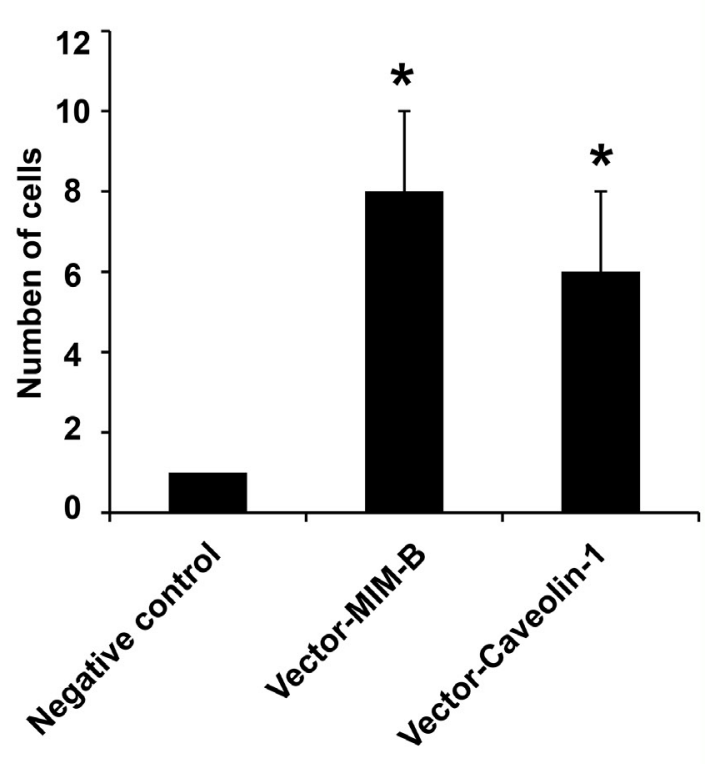

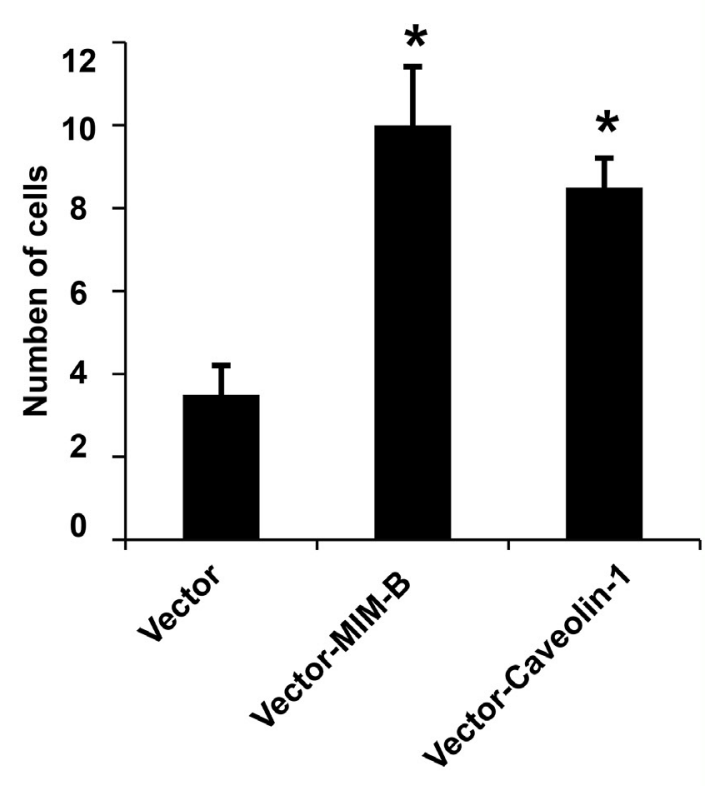

Figure 4: MIM-B and caveolin-1 overexpression promoted Hep3B cell migration. (A) Transwell migration assay of Hep3B cells transfected with pcDNA-MIM-B and pcDNA-caveolin-1 plasmids. (B) Transwell invasion assay of Hep3B cells transfected with pcDNA-MIM-B and pcDNA-caveolin-1 plasmids. ${ }^{*} P<0.05,{ }^{* *} P<0.01$, and each experiment was repeated at least three times. 


\section{DISCUSSION}

In this study, we found that MIM-B could colocalize and interact with caveolin-1 in HCC cells and that inhibiting MIM-B and caveolin-1 had an inhibition effect on EGFR pathway activity. Furthermore, we showed that altering MIM-B and caveolin-1 expression levels could affect MIM-B and caveolin-1 interactions and HCC cell invasion and migration. Through a series of experiments, we found that MIM-B and caveolin-1 expression levels were higher in cancer tissues than in paired adjacent normal tissues and that MIM-B and caveolin-1 expression levels were correlated with HCC clinico-pathologic characteristics.

A

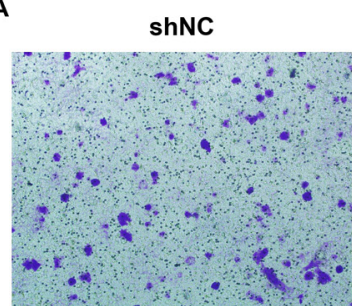

shCaveolin-1

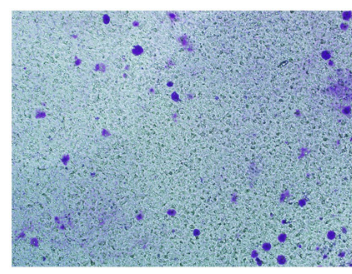

B

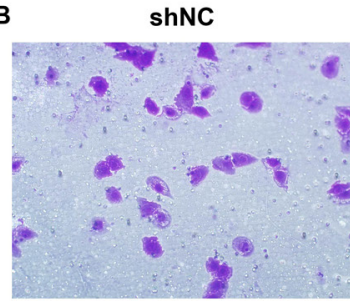

shCaveolin-1

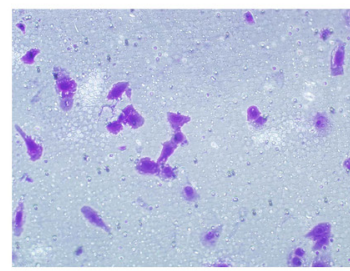

shMIM-B+shCaveolin-1

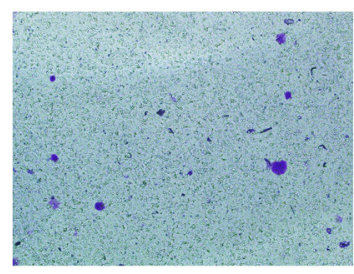

shMIM-B
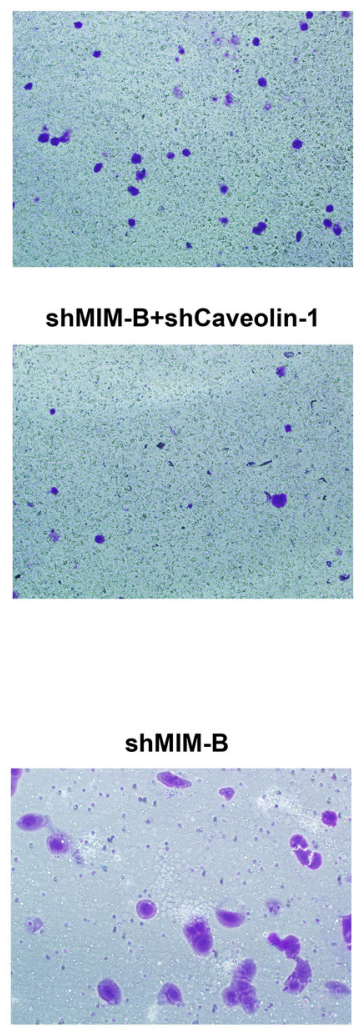

shMIM-B+shCaveolin-1

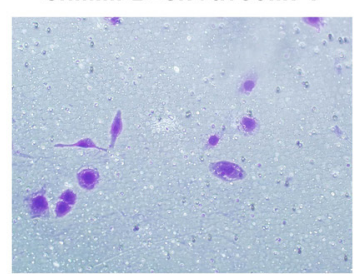

In previous studies, MIM-B was found to act as an actin-monomer binding protein that sequestered actin monomers and induced Rac activation and lamellipodia formation $[15,21]$. However, the mechanism through which MIM-B exerts these effects remains largely unknown. In this study, immunofluorescence assay indicated that caveolin-1 may be an interaction partner for MIM-B (Figure 1A). Furthermore, the results of the co-IP assay demonstrated that MIM-B could interact with caveolin-1 in vitro (Figure 1). These results showed that MIM-B facilitated cell migration by interacting with caveolin-1. Caveolin-1 and MIM-B interact to exert a variety of effects. For example, previous studies reported that caveolin-1-mediated survival downregulation in
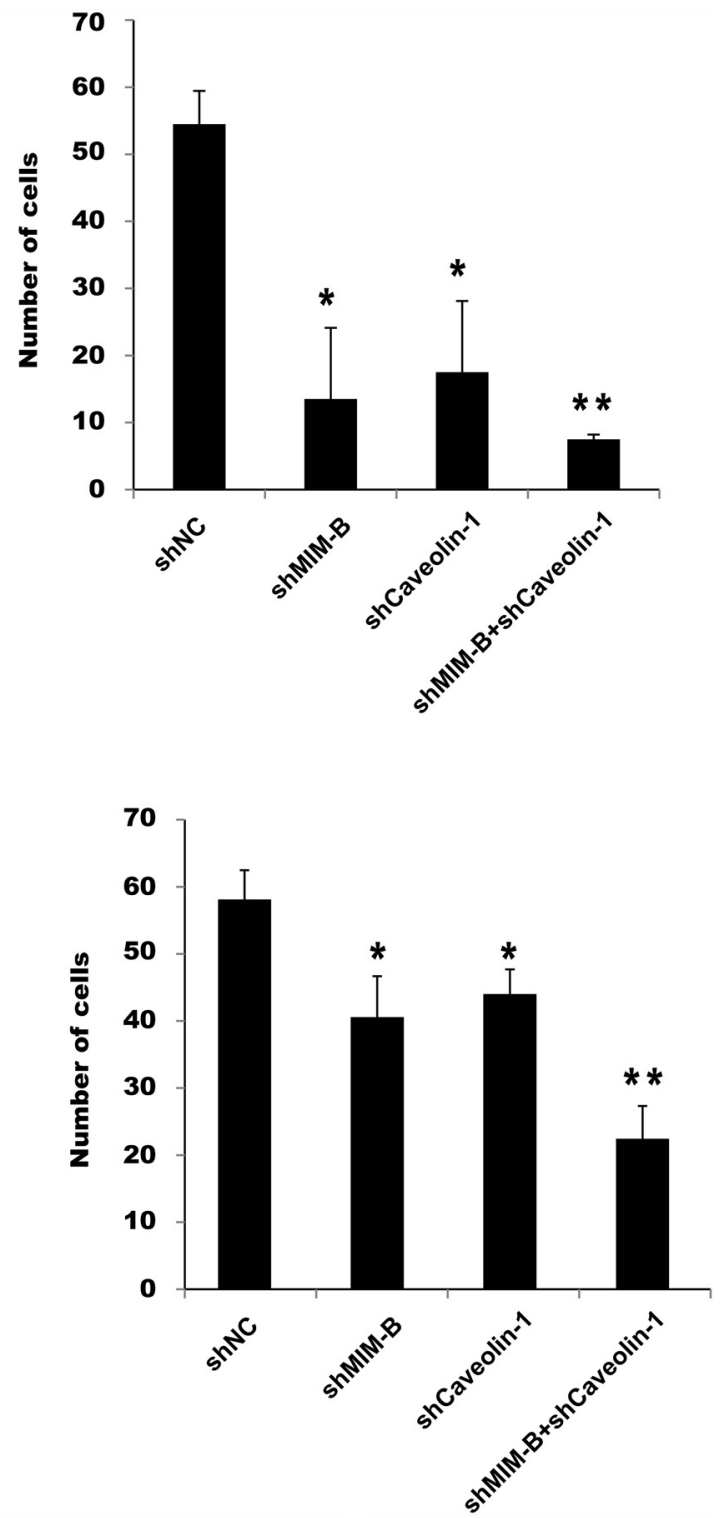

Figure 5: Knocking down MIM-B and caveolin-1 inhibited MHCC97H cell migration and invasion. (A) Transwell migration assay of MHCC97H cells transfected with shMIM-B and shcaveolin-1. (B) Transwell invasion assay of MHCC97H cells transfected with shMIM-B and shcaveolin-1. ${ }^{*} P<0.05,{ }^{* *} P<0.01$, and each experiment was repeated at least three times. 
Table 1: Correlations between MIM-B and caveolin-1 expression and the clinicopathological parameters of patients with HCC

\begin{tabular}{|c|c|c|c|c|c|c|c|c|c|c|c|}
\hline \multirow[t]{2}{*}{ Features } & & \multirow[t]{2}{*}{ No. } & \multicolumn{2}{|c|}{$\begin{array}{c}\text { MIM-B } \\
\text { expression }\end{array}$} & \multirow[t]{2}{*}{$P$} & \multicolumn{2}{|c|}{$\begin{array}{l}\text { Caveolin-1 } \\
\text { expression }\end{array}$} & \multirow[t]{2}{*}{$\boldsymbol{P}$} & \multicolumn{2}{|c|}{$\begin{array}{l}\text { MIM-B and } \\
\text { caveolin-1 } \\
\text { expression }\end{array}$} & \multirow[t]{2}{*}{$P$} \\
\hline & & & High & Low & & High & Low & & Both high & None & \\
\hline \multirow[t]{2}{*}{ Gender } & Male & 73 & 42 & 31 & 0.702 & 45 & 28 & 0.478 & 33 & 40 & 0.988 \\
\hline & Female & 11 & 7 & 4 & & 8 & 3 & & 5 & 6 & \\
\hline \multirow[t]{2}{*}{ Age } & $<60 \mathrm{y}$ & 63 & 34 & 29 & 0.160 & 40 & 23 & 0.896 & 30 & 33 & 0.448 \\
\hline & $\geq 60 y$ & 21 & 15 & 6 & & 13 & 8 & & 8 & 13 & \\
\hline \multirow[t]{2}{*}{ AFP level, ng/ml } & $\leq 20$ & 26 & 14 & 12 & 0.576 & 13 & 13 & 0.096 & 10 & 16 & 0.403 \\
\hline & $>20$ & 58 & 35 & 23 & & 40 & 18 & & 28 & 30 & \\
\hline \multirow[t]{2}{*}{ Cirrhosis } & Yes & 60 & 38 & 22 & 0.142 & 35 & 25 & 0.153 & 31 & 29 & 0.061 \\
\hline & No & 24 & 11 & 13 & & 18 & 6 & & 7 & 17 & \\
\hline \multirow[t]{2}{*}{ Satellite } & Yes & 21 & 17 & 4 & 0.021 & 18 & 3 & 0.018 & 15 & 6 & 0.005 \\
\hline & No & 63 & 32 & 31 & & 35 & 28 & & 23 & 40 & \\
\hline \multirow[t]{2}{*}{ Tumor number } & Multiple & 46 & 35 & 11 & 0.000 & 34 & 12 & 0.024 & 27 & 19 & 0.006 \\
\hline & Single & 38 & 14 & 24 & & 19 & 19 & & 11 & 27 & \\
\hline \multirow[t]{2}{*}{ Encapsulation } & Complete & 33 & 13 & 20 & 0.005 & 15 & 18 & 0.007 & 10 & 23 & 0.027 \\
\hline & Incomplete & 51 & 36 & 15 & & 38 & 13 & & 28 & 23 & \\
\hline \multirow[t]{2}{*}{ Vascular invasion } & Yes & 53 & 41 & 12 & 0.000 & 39 & 14 & 0.009 & 31 & 22 & 0.001 \\
\hline & No & 31 & 8 & 23 & & 14 & 17 & & 7 & 24 & \\
\hline \multirow[t]{2}{*}{ Tumor size } & $<5 \mathrm{~cm}$ & 38 & 25 & 13 & 0.208 & 26 & 12 & 0.358 & 16 & 22 & 0.600 \\
\hline & $\geq 5 \mathrm{~cm}$ & 46 & 24 & 22 & & 27 & 19 & & 22 & 24 & \\
\hline \multirow[t]{4}{*}{$\begin{array}{l}\text { Disease stage } \\
\text { (TNM) }\end{array}$} & I & 10 & 7 & 3 & 0.032 & 6 & 4 & 0.016 & 4 & 6 & 0.002 \\
\hline & II & 25 & 11 & 14 & & 11 & 14 & & 5 & 20 & \\
\hline & III & 33 & 17 & 16 & & 21 & 12 & & 16 & 17 & \\
\hline & IVA & 16 & 14 & 2 & & 15 & 1 & & 13 & 3 & \\
\hline \multirow[t]{3}{*}{ Tumor stage } & $\mathrm{T} 1$ & 12 & 9 & 3 & & 8 & 4 & & 5 & 7 & 0.379 \\
\hline & $\mathrm{T} 2$ & 33 & 22 & 11 & & 25 & 8 & & 18 & 15 & \\
\hline & T3 & 39 & 18 & 21 & & 20 & 19 & & 15 & 24 & \\
\hline
\end{tabular}

NOTE: HCC, hepatocellular carcinoma. No patients had T4 or IVB disease in this study. Significant difference: $P<0.05$.

the presence of E-cadherin coincided with increases in apoptosis facilitated by reductions in beta-catenindependent transcription and that MIM-B co-localized with E-cadherin in MDCK cells [48, 49].

The EGFR pathway plays important roles in a variety of cancers by affecting cell growth, cell metastasis, cell cycle activity, and cell differentiation [36, 39]; however, the mechanism through which the pathway alters the above processes remains largely unknown. The migration and invasion assays demonstrated that inhibiting
MIM-B and caveolin-1 expression inhibited EGFR pathway activity (Figure 3C). Thus, these experiments demonstrated a new means by which the EGFR pathway is regulated in HCC. However, the effects of MIM-B on EGFR pathway activity are often different in different cell types [42]. Our studies provided us with clues regarding the mechanisms underlying the effects of MIM-B and caveolin-1 in HCC and have also provided us with a theoretical basis for studying the clinical applicability of MIM-B/caveolin-1 interactions. 
A

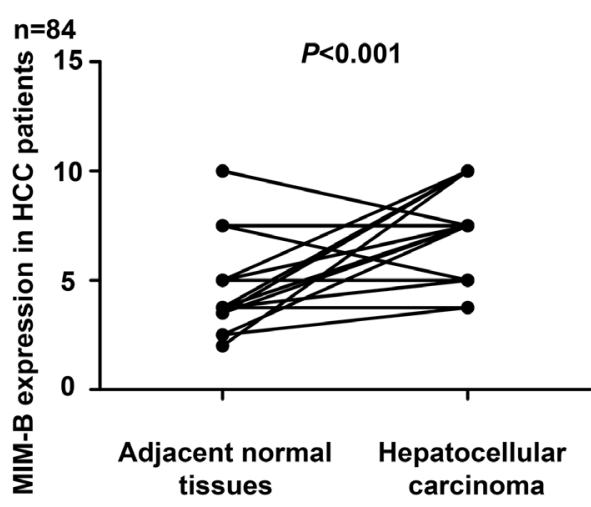

C

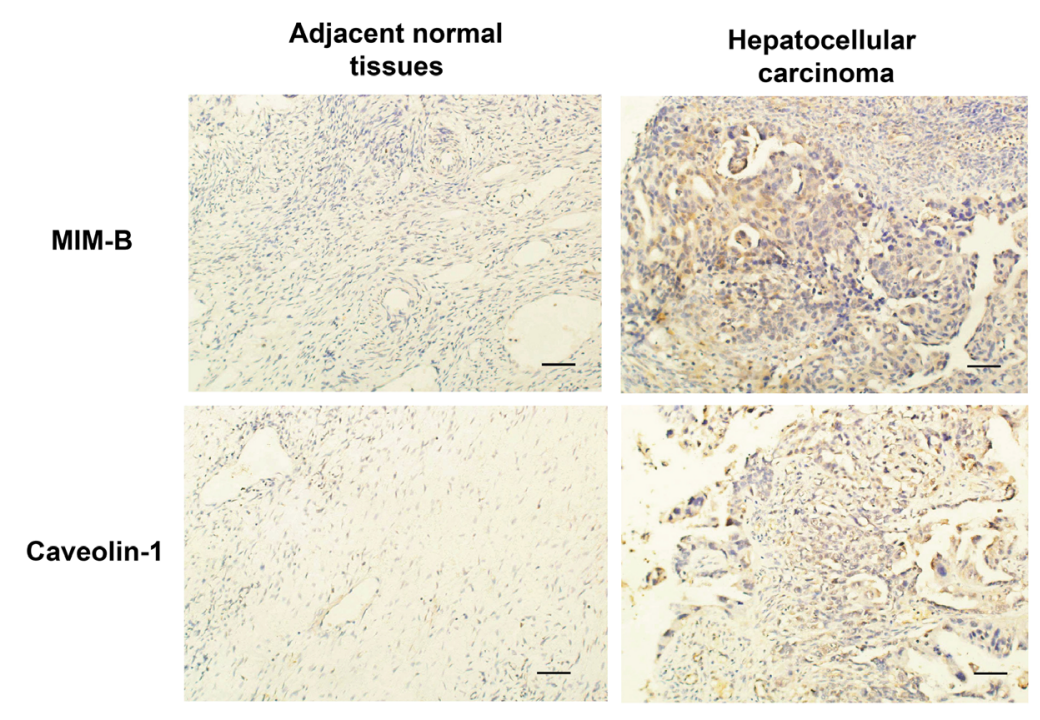

D

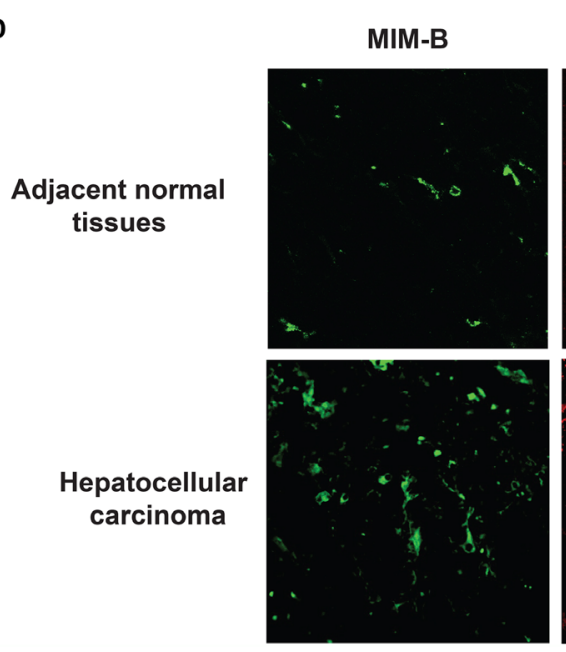

Caveolin-1
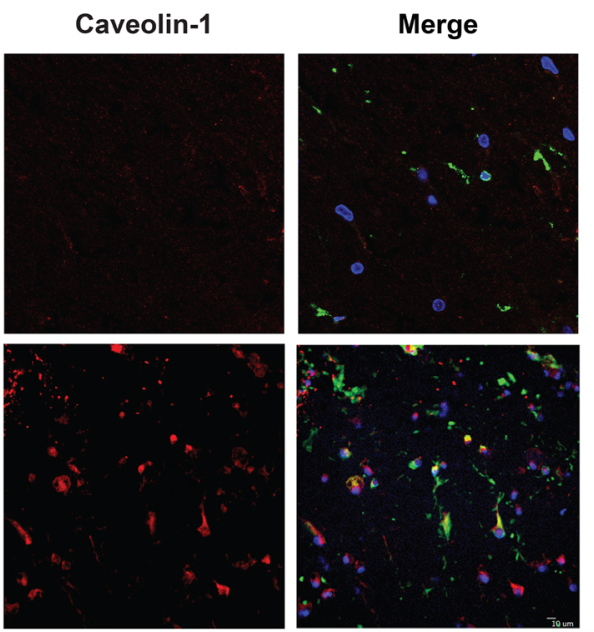

B

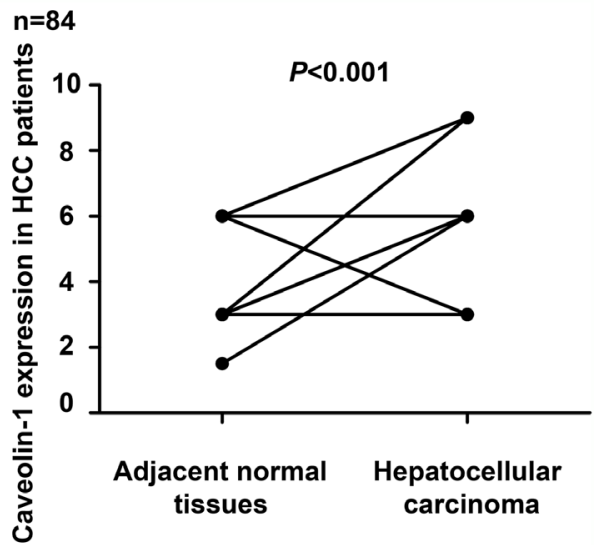

Figure 6: MIM-B and caveolin-1 are aberrantly expressed in HCC. (A) IHC showing that the difference in MIM-B expression levels between HCC tumor tissues and matched adjacent normal tissues is statistically significant $(P<0.001)$. (B) IHC showing that the difference in caveolin-1 expression levels between HCC tumor tissues and matched adjacent normal tissues is statistically significant $(P$ $<0.001$ ). (C) Representative images showing typical MIM-B and caveolin-1 IHC staining patterns in HCC tumors and matched adjacent normal tissues (scale bar, $50 \mu \mathrm{m}$ ). $\mathrm{N}=$ No. of paired samples. (D) MIM-B and caveolin-1 were significantly elevated and co-localized in HCC tissue samples when compared with matched adjacent normal tissues $(P<0.001)$. 
Although MIM-B was found to be a metastasis suppressor gene in bladder cancer, increasing amounts of evidence indicate that its role in cancer cells is a controversial subject [4, 15-17]. The transwell migration assays results demonstrated that downregulating MIM-B could significantly inhibit MHCC97H cell metastasis (Figure 5). The role of caveolin-1 in different cancer cells is also a controversial subject. We found that knocking down caveolin-1 in MHCC97H cells had the same effect as knocking down MIM-B (Figure 5). Our study demonstrated that MIM-B and caveolin-1 could promote MHCC97H cell migration. Consistent with this result, the results of subsequent experiments showed that cell migration ability of MHCC97H cells in which MIM-B and caveolin-1 expression was suppressed was significantly decreased compared with that of cells in which the two proteins were expressed (Figure 5). These results suggested that MIM-B and caveolin-1 play important and similar roles in regulating cell migration.

There are few biomarkers specific for solid tumors such as HCC. Several reports have documented that both MIM-B and caveolin-1 expression levels are significantly altered in various type of cancers and may thus be an independent prognostic factor for different cancers [5054]. In this study, interestingly, we demonstrated that loss of MIM-B, caveolin-1 or both could inhibit MHCC97H cell migration (Figure 5). Furthermore, our study showed that MIM-B expression levels were elevated in 49 of 84 patient samples and that caveolin-1 levels were elevated in 53 of 84 patient samples $(P<0.01)$ (Figure 6A and 6B). All human HCC tissue samples were collected from patients with hepatitis $\mathrm{B}$ virus infection and no patients had T4 or IVB disease in this study. Tumor stage (T stage) means tumor size. MIM-B is not related with T stage,

\section{Survival functions}

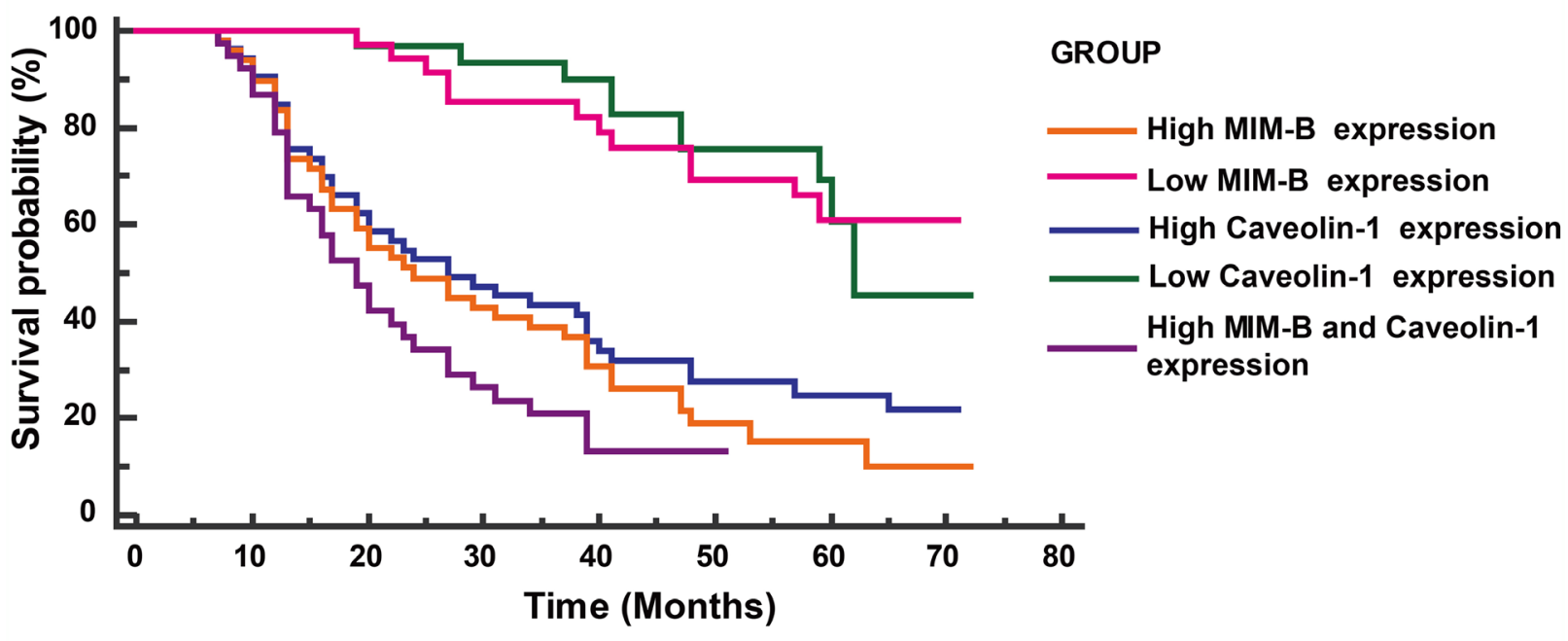

Number at risk:

\begin{tabular}{|c|c|c|c|c|c|c|c|}
\hline \multicolumn{8}{|c|}{ Group: High MIM-B expression } \\
\hline 49 & 44 & 27 & 21 & 14 & 7 & 3 & 1 \\
\hline \multicolumn{8}{|c|}{ Group: Low MIM-B expression } \\
\hline 35 & 35 & 34 & 28 & 25 & 21 & 7 & 1 \\
\hline \multicolumn{8}{|c|}{ Group: High Caveolin-1 expression } \\
\hline 53 & 48 & 31 & 25 & 17 & 12 & 8 & 2 \\
\hline \multicolumn{8}{|c|}{ Group: Low Caveolin-1 expression } \\
\hline 31 & 31 & 30 & 28 & 25 & 21 & 5 & I \\
\hline \multicolumn{8}{|c|}{ Group: High MIM-B and Caveolin-1 expression } \\
\hline 38 & 33 & 16 & 10 & 4 & 2 & 0 & 0 \\
\hline
\end{tabular}

Figure 7: Kaplan-Meier survival plots for patients with different MIM-B and caveolin-1 expression levels. Kaplan-Meier survival analysis (log-rank test) was applied for survival analysis. High MIM-B expression, $\mathrm{n}=49$; high caveolin-1 expression, $\mathrm{n}=53$; low MIM-B expression, $\mathrm{n}=35$; low caveolin-1 expression, $\mathrm{n}=31$; high MIM-B and caveolin-1 expression, $\mathrm{n}=38$. Patients with high MIM-B expression revealed poorer prognosis when compared with patients with low MIM-B expression $(P<0.0001)$; patients with high caveolin-1 expression revealed poorer prognosis when compared with patients with low caveolin-1 expression $(P<0.00001)$. 
but related with TNM stage $(P=0.002)$, encapsulation $(P=0.005)$, vascular invasion $(P=0.000)$, which could be found in Table 1. Our results were consistent with the previous study [14], which demonstrated that MIM-B expression was significantly associated with early pathologic TNM stage group $(P=0.007)$, presence of tumor encapsulation $(P=0.034)$, and absence of venous infiltration $(P=0.038)$.

These results indicated that MIM-B/caveolin-1 expression may be an independent prognostic factor for $\mathrm{HCC}$ and may also be a novel therapeutic target in the treatment of HCC. However, these hypotheses warrant further study, and we are currently designing experiments involving $\mathrm{HCC}$ samples from patients to confirm them.

\section{MATERIALS AND METHODS}

\section{Cells and reagents}

The cell lines used herein were cultured in media, as recommended by the American Type Culture Collection (ATCC). The human HCC cell MHCC97H cell lines was purchased from the Liver Cancer Institute, Shanghai Medical College of Fudan University, and was cultured in DMEM supplemented with 10\% FBS, $100 \mu \mathrm{g} / \mathrm{ml}$ penicillin, $0.1 \mathrm{mg} / \mathrm{ml}$ streptomycin and $2 \mathrm{mM}$ L-glutamine at $37^{\circ} \mathrm{C}$ in a humidified atmosphere containing and $5 \%$ $\mathrm{CO}_{2}$. Puromycin (GM-040401-1) was purchased from Genomeditech (Shanghai, China), and hEGF (SigmaAldrich, St. Louis, MO, USA) was dissolved in a solution of phosphate buffered saline (PBS) $(\mathrm{pH}=7.4)$.

\section{Tissue specimens}

This study was approved by the Research Ethics Committee of Shanghai Jiaotong University Affiliated Sixth People's Hospital. Human HCC tissue samples were collected from patients who underwent surgical resection in Shanghai Jiaotong University Affiliated Sixth People's Hospital and provided informed consent regarding the use of their samples in this study. The criteria used to determine whether patients were eligible for inclusion in this study were reported in a previous study [12]. In brief, the inclusion criteria for patients in this study were (a) pathologically proven HCC based on WHO criteria and UICC-TNM classification; (b) no anticancer treatment prior to hepatectomy; (c) patients with hepatitis B; (d) availability of frozen resected HCC tissues and follow-up data. The samples were collected from 2008 to 2012 and were evaluated until December 31, 2015. All specimens were evaluated and reclassified according to the current WHO and UICC-TNM classifications (Travis et al, 2004) (7th edition; Sobin et al, 2009). Fresh HCC tissues and paired adjacent normal tissues $(\geq 2 \mathrm{~cm}$ away from tumor) were collected in the operating room immediately $(\leq 15 \mathrm{~min})$ after tissue removal and were snapping frozen in liquid nitrogen and stored at $-80^{\circ} \mathrm{C}$ until use. Their histological types were confirmed using standard hematoxylin and eosin staining. A summary of the clinicopathological characteristics of the samples is provided in Table 1.

\section{Plasmid construction, lentivirus production and cell infection}

The MIM-B and caveolin-1 expression plasmids used herein were based on the pLVX-puro-EGFP lentiviral vector. The following MIM-B primers were used in this study: F: 5'- CTAGCTAGCATGGAGGCTGTGATTGAG AAGG-3' and R: 5'- CGGGATCCCTAAGAAAAGCGA GGGGCTGAG- ${ }^{\prime}$. The following caveolin-1 primers were used in this study: F: 5'-CTAGCTAGCATGTCTGGGGG CAAATACGTAG-3' and R: 5'- CGGGATCCTTATATTT CTTTCTGCAAGTTGATGCGG-3'.

MIM-B and caveolin-1-specific small-hairpin RNA (shRNA) sequences, which were synthesized by General Biosystems (Anhui), were ligated into a pLKO.1 lentiviral vector. The MIM-B sequences were as follows: sense: 5'-GATCCCCGTAGATGCATTGTAGTAGT-3', and antisense: $5^{\prime}$-ACTACTACAATGCATCTACGGGGA TC-3'. The caveolin-1 sequences were as follows: sense: 5'-GATCCCCAACCAGAAGGGACACACAGTT-3', and antisense: 5'-AACTGTGTGTCCCTTCTGGTTGGGGA TC-3'.

The lentiviruses were produced as follow: shuttle vectors and helper plasmids were transfected into 293FT cells for $48 \mathrm{~h}$ with Lipofectamine 2000, according to the manufacturer's instructions (Invitrogen, USA). The cells were seeded in the appropriate plates for approximately $18 \mathrm{~h}$ before being transfected with the indicated plasmids.

We constructed MIM-B gene fragments lacking the sequences for the IMD or WH2 motifs and inserted these fragments into a pcDNA-3.1 plasmid. Specifically, the MIM-IMD.ko and MIM-WH2.ko fragments were amplified and inserted into the indicated plasmid, which contained BamHI/XhoI restriction sites. The plasmids were then transfected into the above cells for further research.

\section{RNA extraction and quantitative real-time PCR}

Total RNA was extracted with TRIzol regent (Invitrogen), according to the manufacturer's instructions. One microgram of RNA was subsequently reverse transcribed into cDNA with a Takara PrimeScript RT Regent Kit (Takara), and the cDNA was amplified by real-time PCR on an Applied Biosystems 7500 (Applied Biosystems). GAPDH was used as a control, and the normalized expression levels of the target genes were expressed using arbitrary units. The following primers for MIM-B were used in the experiment: F: 5'-TGCAGAAGAAAGCAAA-3' 
and R: 5'-GGAGAGCACTGTCCAACTGA-3'. The following primers for caveolin-1 were used in the experiment: F: 5'-TCTTTGGCATCCCGATGG-3' and R: 5'-GTTGATGCGGACATTGCT-3'. The following primers for GAPDH were used in the experiment: F: 5'-GCACCGTCAAGGCTGAGAAC-3' and R: 5'-ATGGTGGTGAAGACGCCAGT-3'.

\section{Western blotting}

Western blot analysis was performed as described previously [55]. The following antibodies, which were supplied by Abcam (Cambridge, UK), were used in this experiment: anti-MIM-B (Abcam78161), anti-caveolin-1 (Abcam2910), anti-p-EGFR(Abcam52894), anti-EGFR (Abcam52894), anti-p-STAT3 (Abcam76315), anti-STAT3 (Abcam119352), anti-p-AKT (Abcam38449), anti-AKT (Abcam8805), anti-p-ERK (Abcam176660), and antiERK (Abcam54230). Anti-Actin (Rabbit, DH0251\#), anti-GAPDH (Rabbit, DH0261\#) and ECL for Western Blotting Substrate (DH0101) were also used in this experiment and were supplied by Donghuan Biotech Co., Ltd (Shanghai).

\section{Co-immunoprecipitation (Co-IP) assay}

Cultured cells were washed twice with ice-cold PBS and then lysed in $500 \mu \mathrm{l}$ of ice-cold RIPA lysis buffer (1\% NP-40, 50 mM Tris- $\mathrm{HCl}(\mathrm{pH} 7.4), 150 \mathrm{mM}$ $\mathrm{NaCl}, 1 \mathrm{mM}$ EDTA, $0.5 \mathrm{mM}$ PMSF, $1 \mathrm{mM}$ DTT and $1 \times$ Protein Inhibitor (Roche)). The whole-cell lysates were subsequently centrifuged at $12,000 \mathrm{rpm}$ for $10 \mathrm{~min}$ at $4^{\circ} \mathrm{C}$, after which the cell supernatant was subjected to immunoprecipitation with the appropriate primary antibody for $1 \mathrm{~h}$ at $4^{\circ} \mathrm{C}$ before being captured with protein A/G-coupled sepharose beads. After being washed 4 times with ice-cold lysis buffer, the beads were re-suspended in protein loading buffer and then subjected to western blot analysis.

\section{Immunofluorescence staining and confocal microscopy}

After being washed with PBS, cultured MHCC97H cells were fixed with 4\% PFA (in PBS) for $10 \mathrm{~min}$ before being permeabilized with PBS- $0.5 \%$ Triton and blocked with PBS-5\% inactivated goat serum for $1 \mathrm{~h}$. The cells were then incubated in PBS containing 5\% BSA and the appropriate primary antibodies for at least $2 \mathrm{~h}$ at room temperature, after which they were incubated with the appropriate IgGAlexafluorescent-conjugated secondary antibodies for $1 \mathrm{~h}$. The nuclei were stained with DAPI for $5 \mathrm{~min}$, and then the cells were mounted with cover slips after being washed with PBS. For protein expression and colocalization in HCC and the adjacent normal tissue samples, sections were incubated in a hydrogen peroxide solution $(0.3 \%)$ for 1 hour at room temperature. The slides were then analyzed with a confocal microscope (Leica) using a $63 \times$ magnification lens.

\section{Cell migration and invasion}

Cell migration and invasion assays were performed with a transwell apparatus (Millipore), according to the manufacturer's instructions. Briefly, after being serum starved for $24 \mathrm{~h}$, the cells were seeded in the top chamber of the transwell apparatus, which was coated with collagen IV, and medium containing fibronectin was added to the bottom chamber of the apparatus. The cells were subsequently incubated for $48 \mathrm{~h}$ at $37^{\circ} \mathrm{C}$ and then fixed with $0.1 \%$ methanol for $10 \mathrm{~min}$ before being stained with hematoxylin. The non-migrating cells on top of each filter were removed with a cotton swab. The migrating cells were counted, and the results were expressed as the ratio of migrating or invading cells: control cells.

\section{Immunohistochemistry (IHC)}

IHC was performed as previously described [56]. Anti-MIM-B antibodies (Abcam, abcam78161) were used to identify MIM-B, and anti-caveolin-1 antibodies (Abcam, abcam2910) were used to identify caveolin-1. MIM-B and caveolin-1 expression scores were calculated as the product of the cell staining percentage and cell staining intensity. The cell staining intensity was scored as follows: $($ none $)=0,($ weak $)=1,($ medium $)=2$, and (strong) $=3$, and the cell staining percentage was scored as follows: $<33 \%=1,33-66 \%=2$, and $\geq 66 \%=3$. The expression scores were calculated using the following equation: expression score $=$ staining intensity $\times$ staining percentage. Scores $\geq 3$ were considered "high" scores, while lower scores were considered "low" scores. MIM-B and caveolin-1 expression scores were determined independently by two researchers.

\section{Data analysis}

Survival analysis was conducted using the KaplanMeier method (log-rank test). The data are presented as the mean \pm standard deviation and are representative of at least three experiments. Differences between two groups were evaluated using Student's $t$-test, and all $P$ values were two-tailed. The symbol ${ }^{*}$ denoted a significant difference $(P<0.05)$, while ${ }^{* *}$ denoted a very significant difference $(P<0.01)$.

\section{Abbreviations \\ Hepatocellular carcinoma: HCC; Missing in metastasis B: MIM-B; Epidermal growth factor receptor: EGFR; Epidermal growth factor: EGF; Co- immunoprecipitation: Co-IP; Small hairpin RNA: shRNA; Negative control shRNA: shNC.}




\section{Author contributions}

Conceived and designed the experiments: $\mathrm{X}-\mathrm{YH}$, Z-LH, ZC and Z-YT; performed the experiments: X-YH, Z-LH, TN, Z-QW and BX; analyzed the data: X-YH, Z-LH, BX, ZC and Y-HX; contributed reagents/materials/ analysis tools: $\mathrm{X}-\mathrm{YH}, \mathrm{Z}-\mathrm{LH}, \mathrm{X}-\mathrm{YH}, \mathrm{QZ}, \mathrm{JZ}$ and Z-YT; and wrote the paper: X-YH, Z-LH, JZ, ZC and Z-YT.

\section{ACKNOWLEDGMENTS}

The authors appreciate the contributions of all the investigators at all participating study sites.

\section{CONFLICTS OF INTEREST} exist.

The authors declare that no competing interests

\section{FUNDING (GRANT SUPPORT)}

This study was supported by grants from the National Natural Science Foundation of China (No. 81272401); the International Foundation of Translational Medicine for Scholars and Students Studying in the U.S. and China (No. UCTMP2015-03C001); the Foundation of Shanghai Health Bureau, Shanghai, PR China (No. 2012QJ001A); and the National Natural Science Foundation of China (No. 8150040130). Z.C. appreciates the support from the National Cancer Institute of the National Institutes of Health (Award No. U01CA202123) and the Society in Science Branco Weiss Fellowship, which was awarded by ETH Zürich.

\section{REFERENCES}

1. Wang X, Zhang A, Sun H. Power of metabolomics in diagnosis and biomarker discovery of hepatocellular carcinoma. Hepatology. 2013; 57:2072-7. https://doi. org/10.1002/hep.26130.

2. Guo Y, Wang J, Zhang L, Shen S, Guo R, Yang Y, Chen W, Wang Y, Chen G, Shuai X. Theranostical nanosystemmediated identification of an oncogene and highly effective therapy in hepatocellular carcinoma. Hepatology. 2016; 63:1240-55. https://doi.org/10.1002/hep.28409.

3. Ferrer-Fàbrega J, Forner A, Liccioni A, Miquel R, Molina V, Navasa M, Fondevila C, García-Valdecasas JC, Bruix J, Fuster J. Prospective validation of ab initio liver transplantation in hepatocellular carcinoma upon detection of risk factors for recurrence after resection. Hepatology. 2016; 63:839-49. https://doi.org/10.1002/hep.28339.

4. Lee YG, Macoska JA, Korenchuk S, Pienta KJ. MIM, a potential metastasis suppressor gene in bladder cancer. Neoplasia. 2002; 4:291-4. https://doi.org/10.1038/ sj.neo.7900231.
5. Li XD, Zhang JX, Jiang LJ, Wang FW, Liu LL, Liao YJ, Jin XH, Chen WH, Chen X, Guo SJ, Zhou FJ, Zeng YX, Guan $\mathrm{XY}$, et al. Overexpression of maelstrom promotes bladder urothelial carcinoma cell aggressiveness by epigenetically downregulating MTSS1 through DNMT3B. Oncogene. 2016; 35:6281-92. https://doi.org/10.1038/onc.2016.165.

6. Wang Y, Liu J, Smith E, Zhou K, Liao J, Yang GY, Tan $\mathrm{M}$, Zhan X. Downregulation of missing in metastasis gene (MIM) is associated with the progression of bladder transitional carcinomas. Cancer Invest. 2007; 25:79-86. https://doi.org/10.1080/07357900701205457.

7. Callahan CA, Ofstad T, Horng L, Wang JK, Zhen $\mathrm{HH}$, Coulombe PA, Oro AE. MIM/BEG4, a Sonic hedgehog-responsive gene that potentiates Gli-dependent transcription. Genes Dev. 2004; 18:2724-9. https://doi. org/10.1101/gad.1221804.

8. Kelley LC, Shahab S, Weed SA. Actin cytoskeletal mediators of motility and invasion amplified and overexpressed in head and neck cancer. Clinical Exp metastasis. 2008; 25:289-304. https://doi.org/10.1007/ s10585-008-9154-6.

9. Liu K, Wang G, Ding H, Chen Y, Yu G, Wang J. Downregulation of metastasis suppressor 1 (MTSS1) is associated with nodal metastasis and poor outcome in Chinese patients with gastric cancer. BMC cancer. 2010; 10:428. https://doi.org/10.1186/1471-2407-10-428.

10. Loberg RD, Neeley CK, Adam-Day LL, Fridman Y, St John LN, Nixdorf S, Jackson P, Kalikin LM, Pienta KJ. Differential expression analysis of MIM (MTSS1) splice variants and a functional role of MIM in prostate cancer cell biology. Int J Oncol. 2005; 26:1699-705.

11. Parr C, Jiang WG. Metastasis suppressor 1 (MTSS1) demonstrates prognostic value and anti-metastatic properties in breast cancer. Eur J cancer. 2009; 45:1673-83. https://doi.org/10.1016/j.ejca.2009.02.019.

12. Huang XY, Huang ZL, Xu B, Chen Z, Re TJ, Zheng Q, Tang ZY, Huang XY. Elevated MTSS1 expression associated with metastasis and poor prognosis of residual hepatitis B-related hepatocellular carcinoma. J Exp Clin Cancer Res. 2016; 35:85. https://doi.org/10.1186/s13046-016-0361-8.

13. Guo Y, Ren MS, Shang C, Zhu L, Zhong M. MTSS1 gene regulated by miR-96 inhibits cell proliferation and metastasis in tongue squamous cellular carcinoma Tca8113 cell line. Int J Clin Exp Med. 2015; 8:15441-9.

14. Ma S, Guan XY, Lee TK, Chan KW. Clinicopathological significance of missing in metastasis B expression in hepatocellular carcinoma. Hum Pathol. 2007; 38:1201-6. https://doi.org/10.1016/j.humpath.2007.01.004.

15. Bompard G, Sharp SJ, Freiss G, Machesky LM. Involvement of Rac in actin cytoskeleton rearrangements induced by MIM-B. J Cell Sci. 2005; 118:5393-403. https:// doi.org/10.1242/jcs.02640.

16. Gonzalez-Quevedo R, Shoffer M, Horng L, Oro AE. Receptor tyrosine phosphatase-dependent cytoskeletal 
remodeling by the hedgehog-responsive gene MIM/BEG4. J Cell Biol. 2005; 168:453-63. https://doi.org/10.1083/ jcb.200409078.

17. Machesky LM, Johnston SA. MIM: a multifunctional scaffold protein. J Mol Med (Berl). 2007; 85:569-76. https://doi.org/10.1007/s00109-007-0207-0.

18. Millard TH, Bompard G, Heung MY, Dafforn TR, Scott DJ, Machesky LM, Fütterer K. Structural basis of filopodia formation induced by the IRSp53/MIM homology domain of human IRSp53. EMBO J. 2005; 24:240-50. https://doi. org/10.1038/sj.emboj.7600535.

19. Lee SH, Kerff F, Chereau D, Ferron F, Klug A, Dominguez R. Structural basis for the actin-binding function of missingin-metastasis. Structure. 2007; 15:145-55. https://doi. org/10.1016/j.str.2006.12.005.

20. Dawson JC, Timpson P, Kalna G, Machesky LM. Mtss1 regulates epidermal growth factor signaling in head and neck squamous carcinoma cells. Oncogene. 2012; 31:178193. https://doi.org/10.1038/onc.2011.376.

21. Woodings JA, Sharp SJ, Machesky LM. MIM-B, a putative metastasis suppressor protein, binds to actin and to protein tyrosine phosphatase delta. Biochem J. 2003; 371:463-71. https://doi.org/10.1042/BJ20021962.

22. Saarikangas J, Kourdougli N, Senju Y, Chazal G, Segerstråle M, Minkeviciene R, Kuurne J, Mattila PK, Garrett L, Hölter SM, Becker L, Racz I, Hans W, et al. MIM-Induced membrane bending promotes dendritic spine initiation. Dev Cell. 2015; 33:644-59. https://doi. org/10.1016/j.devcel.2015.04.014.

23. Parton RG, del Pozo MA. Caveolae as plasma membrane sensors, protectors and organizers. Nat Rev Mol Cell Biol. 2013; 14:98-112. https://doi.org/10.1038/nrm3512.

24. Okamoto T, Schlegel A, Scherer PE, Lisanti MP. Caveolins, a family of scaffolding proteins for organizing "preassembled signaling complexes" at the plasma membrane. J Biol Chem. 1998; 273:5419-22.

25. Bourseau-Guilmain E, Menard JA, Lindqvist E, Indira Chandran V, Christianson HC, Cerezo Magaña M, Lidfeldt J, Marko-Varga G, Welinder C, Belting M. Hypoxia regulates global membrane protein endocytosis through caveolin-1 in cancer cells. Nat Commun. 2016; 7:11371. https://doi.org/10.1038/ncomms11371.

26. Li Z, Scott MJ, Fan EK, Li Y, Liu J, Xiao G, Li S, Billiar TR, Wilson MA, Jiang Y, Fan J. Tissue damage negatively regulates LPS-induced macrophage necroptosis. Cell Death Differ. 2016; 23:1428-47. https://doi.org/10.1038/ cdd.2016.21.

27. Kang J, Park JH, Lee HJ, Jo U, Park JK, Seo JH, Kim YH, Kim I, Park KH. Caveolin-1 modulates docetaxel-induced cell death in breast cancer cell subtypes through different mechanisms. Cancer Res Treat. 2016; 48:715-26. https:// doi.org/10.4143/crt.2015.227

28. Yamaguchi T, Lu C, Ida L, Yanagisawa K, Usukura J, Cheng J, Hotta N, Shimada Y, Isomura H, Suzuki M,
Fujimoto T, Takahashi T. ROR1 sustains caveolae and survival signalling as a scaffold of cavin-1 and caveolin-1. Nat Commun. 2016; 7:10060. https://doi.org/10.1038/ ncomms 10060 .

29. Conde-Perez A, Gros G, Longvert C, Pedersen M, Petit V, Aktary Z, Viros A, Gesbert F, Delmas V, Rambow F, Bastian BC, Campbell AD, Colombo S, et al. A caveolin-dependent and PI3K/AKT-independent role of PTEN in beta-catenin transcriptional activity. Nat Commun. 2015; 6:8093. https:// doi.org/10.1038/ncomms9093.

30. Zhang PX, Cheng J, Zou S, D'Souza AD, Koff JL, Lu J, Lee PJ, Krause DS, Egan ME, Bruscia EM. Pharmacological modulation of the AKT/microRNA-199a-5p/CAV1 pathway ameliorates cystic fibrosis lung hyper-inflammation. Nat Commun. 2015; 6:6221. https://doi.org/10.1038/ ncomms 7221 .

31. Hall DP, Cost NG, Hegde S, Kellner E, Mikhaylova O, Stratton Y, Ehmer B, Abplanalp WA, Pandey R, Biesiada J, Harteneck C, Plas DR, Meller J, et al. TRPM3 and miR-204 establish a regulatory circuit that controls oncogenic autophagy in clear cell renal cell carcinoma. Cancer Cell. 2014; 26:738-53. https://doi.org/10.1016/j. ccell.2014.09.015.

32. Tse EY, Ko FC, Tung EK, Chan LK, Lee TK, Ngan ES, Man $\mathrm{K}$, Wong AS, Ng IO, Yam JW. Caveolin-1 overexpression is associated with hepatocellular carcinoma tumourigenesis and metastasis. J Pathol. 2012; 226:645-53. https://doi. org/10.1002/path.3957.

33. Zhang ZB, Cai L, Zheng SG, Xiong Y, Dong JH. Overexpression of caveolin-1 in hepatocellular carcinoma with metastasis and worse prognosis: correlation with vascular endothelial growth factor, microvessel density and unpaired artery. Pathol Oncol Res. 2009; 15:495-502. https://doi.org/10.1007/s12253-008-9144-7.

34. Cokakli M, Erdal E, Nart D, Yilmaz F, Sagol O, Kilic M, Karademir S, Atabey N. Differential expression of Caveolin-1 in hepatocellular carcinoma: correlation with differentiation state, motility and invasion. BMC cancer. 2009; 9:65. https://doi.org/10.1186/1471-2407-9-65.

35. Yan J, Lu Q, Dong J, Li X, Ma K, Cai L. Hepatitis B virus X protein suppresses caveolin-1 expression in hepatocellular carcinoma by regulating DNA methylation. BMC cancer. 2012; 12:353. https://doi.org/10.1186/1471-2407-12-353.

36. Dazzi H, Hasleton PS, Thatcher N, Barnes DM, Wilkes S, Swindell R, Lawson RA. Expression of epidermal growth factor receptor (EGF-R) in non-small cell lung cancer. Use of archival tissue and correlation of EGF-R with histology, tumour size, node status and survival. Br J Cancer. 1989; 59:746-9.

37. Mak MP, William WN Jr. Targeting the epidermal growth factor receptor for head and neck cancer chemoprevention. Oral Oncol. 2014; 50:918-23. https://doi.org/10.1016/j. oraloncology.2013.12.024.

38. Altimari A, Fiorentino M, Gabusi E, Gruppioni E, Corti B, D'Errico A, Grigioni WF. Investigation of ErbB1 and 
ErbB2 expression for therapeutic targeting in primary liver tumours. Dig Liver Dis. 2003; 35:332-8.

39. Jia Y, Yun CH, Park E, Ercan D, Manuia M, Juarez J, Xu C, Rhee K, Chen T, Zhang H, Palakurthi S, Jang J, Lelais G, et al. Overcoming EGFR (T790M) and EGFR (C797S) resistance with mutant-selective allosteric inhibitors. Nature. 2016; 534:129-32. https://doi.org/10.1038/ nature 17960.

40. Mertins P, Mani DR, Ruggles KV, Gillette MA, Clauser KR, Wang P, Wang X, Qiao JW, Cao S, Petralia F, Kawaler E, Mundt F, Krug K, et al. Proteogenomics connects somatic mutations to signalling in breast cancer. Nature. 2016; 534:55-62. https://doi.org/10.1038/nature18003.

41. Quinones GA, Jin J, Oro AE. I-BAR protein antagonism of endocytosis mediates directional sensing during guided cell migration. J Cell Biol. 2010; 189:353-67. https://doi. org/10.1083/jcb.200910136.

42. Lam DC, Girard L, Suen WS, Chung LP, Tin VP, Lam WK, Minna JD, Wong MP. Establishment and expression profiling of new lung cancer cell lines from Chinese smokers and lifetime never-smokers. J Thorac Oncol. 2006; 1:932-42.

43. Sigismund S, Woelk T, Puri C, Maspero E, Tacchetti C, Transidico P, Di Fiore PP, Polo S. Clathrin-independent endocytosis of ubiquitinated cargos. Proc Natl Acad Sci USA. 2005; 102:2760-5. https://doi.org/10.1073/ pnas.0409817102.

44. Huang F, Khvorova A, Marshall W, Sorkin A. Analysis of clathrin-mediated endocytosis of epidermal growth factor receptor by RNA interference. J Biol Chem. 2004; 279:16657-61. https://doi.org/10.1074/jbc.C400046200.

45. Schmidt-Glenewinkel H, Reinz E, Bulashevska S, Beaudouin J, Legewie S, Alonso A, Eils R. Multiparametric image analysis reveals role of Caveolin1 in endosomal progression rather than internalization of EGFR. FEBS Lett. 2012; 586:1179-89. https://doi.org/10.1016/j. febslet.2012.02.041.

46. Ford MG, Pearse BM, Higgins MK, Vallis Y, Owen DJ, Gibson A, Hopkins CR, Evans PR, McMahon HT. Simultaneous binding of PtdIns (4, 5) P2 and clathrin by AP180 in the nucleation of clathrin lattices on membranes. Science. 2001; 291:1051-5. https://doi.org/10.1126/ science.291.5506.1051.

47. Mattila PK, Salminen M, Yamashiro T, Lappalainen P. Mouse MIM, a tissue-specific regulator of cytoskeletal dynamics, interacts with ATP-actin monomers through its C-terminal WH2 domain. J Biol Chem. 2003; 278:8452-9. https://doi.org/10.1074/jbc.M212113200.
48. Torres VA, Tapia JC, Rodriguez DA, Lladser A, Arredondo C, Leyton L, Quest AF. E-cadherin is required for caveolin1-mediated down-regulation of the inhibitor of apoptosis protein survivin via reduced beta-catenin-Tcf/Lef-dependent transcription. Mol Cell Biol. 2007; 27:7703-17. https://doi. org/10.1128/MCB.01991-06.

49. Saarikangas J, Mattila PK, Varjosalo M, Bovellan M, Hakanen J, Calzada-Wack J, Tost M, Jennen L, Rathkolb B, Hans W, Horsch M, Hyvönen ME, Perälä N, et al. Missingin-metastasis MIM/MTSS1 promotes actin assembly at intercellular junctions and is required for integrity of kidney epithelia. J Cell Sci. 2011; 124:1245-55. https://doi. org/10.1242/jcs.082610.

50. Kayser G, Csanadi A, Kakanou S, Prasse A, Kassem A, Stickeler E, Passlick B, Zur Hausen A. Downregulation of MTSS1 expression is an independent prognosticator in squamous cell carcinoma of the lung. Br J Cancer. 2015; 112:866-73. https://doi.org/10.1038/bjc.2015.2.

51. Wang F, Liu Y, Zhang H. Loss of MTSS1 expression is an independent prognostic factor for Hilar cholangiocarcinoma. Pathol Oncol Res. 2013; 19:815-20. https://doi.org/10.1007/ s12253-013-9649-6.

52. Wang $\mathrm{D}, \mathrm{Xu}$ MR, Wang $\mathrm{T}, \mathrm{Li} \mathrm{T}, \mathrm{Zhu}$ JW. MTSS 1 overexpression correlates with poor prognosis in colorectal cancer. J Gastrointest Surg. 2011; 15:1205-12. https://doi. org/10.1007/s11605-011-1546-2.

53. Mathieu R, Klatte T, Lucca I, Mbeutcha A, Seitz C, Karakiewicz PI, Fajkovic H, Sun M, Lotan Y, Scherr DS, Montorsi F, Briganti A, Rouprêt M, et al. Prognostic value of Caveolin-1 in patients treated with radical prostatectomy: a multicentric validation study. BJU Int. 2015; 118:243-9. https://doi.org/10.1111/bju.13224.

54. Tas F, Karabulut S, Tilgen Yasasever C, Duranyildiz D. Clinical significance of serum caveolin-1 levels in melanoma patients. Int J Dermatol. 2016; 55:558-62. https://doi.org/10.1111/ijd.12862.

55. Yan J, Xiang J, Lin Y, Ma J, Zhang J, Zhang H, Sun J, Danial NN, Liu J, Lin A. Inactivation of BAD by IKK inhibits TNFalpha-induced apoptosis independently of NF-kappaB activation. Cell. 2013; 152:304-15. https://doi. org/10.1016/j.cell.2012.12.021.

56. Jiao S, Wang H, Shi Z, Dong A, Zhang W, Song X, He F, Wang Y, Zhang Z, Wang W, Wang X, Guo T, Li P, et al. A peptide mimicking VGLL4 function acts as a YAP antagonist therapy against gastric cancer. Cancer Cell. 2014; 25:166-80. https://doi.org/10.1016/j.ccr.2014.01.010. 